\title{
“Todo Mundo Quer Ter um Filho Perfeito": Vivências de Mães de Crianças com Autismo
}

\author{
Teresinha Cid Constantinidis - Universidade Federal do Espírito Santo, Vitória, Brasil \\ Laila Cristina da Silva - Universidade Federal do Espirito Santo, Vitória, Brasil \\ Maria Cristina Cardoso Ribeiro - Universidade Federal do Espírito Santo, Vitória, Brasil
}

\begin{abstract}
Resumo
O objetivo deste artigo é compreender a vivência de mães de crianças com autismo, com base em entrevistas e estudos existentes, situando o debate teórico em torno desse processo. Trata-se de pesquisa qualitativa, realizada por meio de entrevistas semiestruturadas com seis mães de crianças com autismo. O tratamento do material deu-se por intermédio da análise de conteúdo, resultando em três temas - impacto do diagnóstico de autismo, suporte social e ser mulher e mãe de criança com autismo. Os resultados corroboram dados da literatura quanto ao impacto do autismo no cotidiano dessas mulheres, aos encargos enfrentados por elas e à importância da rede social de apoio. Destaca-se como achados deste estudo, a importância do diagnóstico como norteador das ações dessas mães e a resistência dos profissionais em fornecê-lo, além do pai da criança com dificuldades em aceitar a condição do filho, mas resgatando a identidade feminina dessa mãe.
\end{abstract}

Palavras-chave: autismo, relações mãe-criança, maternidade

\section{“Everyone Wants To Have a Perfect Child": Being Mother of Children with Autism}

\begin{abstract}
This article aims to understand the aspects of the experience of mothers of children with autism, based on interviews and existing studies, situating the theoretical debate around this process. This is a qualitative research, carried out through semistructured interviews with six mothers of children with autism. Data analysis was conducted using the content analysis method, resulting in three themes - impact of diagnosis, social support, and being a woman and mother of a child with autism. The results corroborate the literature on the impact of autism on the daily lives of these women, the burden they face and the importance of the social support network. The findings of this study emphasize the importance of diagnosis as a guideline for these mothers'actions and the professionals' resistance to provide it, as well as the father who has difficulty accepting the child's condition, and restoring the mother's feminine identity.

Keywords: autism, mother-child relations, maternity
\end{abstract}

“Todo el Mundo Quiere Tener un Hijo Perfecto”: Vivencias de Madres de Niños con Autismo

\begin{abstract}
Resumen
El estudio adaptó y reunió evidencias de validez de estructura interna, convergente y de consistencia interna de la Escala de Pasión por el Trabajo en el contexto brasileño. La muestra fue compuesta por 504 trabajadores brasileños de ambos sexos ( $55 \%$ sexo femenino) con edad media de 33,32 años. Los participantes respondieron presencialmente y en la versión online a instrumentos para evaluar la pasión por el trabajo y las actitudes y sentimientos positivos y negativos direccionados al mismo. Análisis factoriales confirmatorios mostraron que la escala reprodujo integralmente la estructura original del instrumento, compuesto por 14 ítems y dos factores ( Pasión Armoniosa y Pasión Obsesiva). Tales dimensiones mostraron correlaciones positivas o negativas con actitudes y sentimientos positivos o negativos direccionados al trabajo, como estaba previsto por las hipótesis. Se llegó a la conclusión de que el instrumento presentó propiedades psicométricas que recomiendan su uso en futuras investigaciones destinadas a evaluar el grado de pasión por el trabajo.

Palabras-clave: validez estadística; psicometría; salud del trabajador; calidad de vida
\end{abstract}

\section{Introdução}

O autismo é um transtorno caracterizado por um comprometimento acentuado em diversas áreas do desenvolvimento. Segundo o Manual Diagnóstico e Estatístico de Transtornos Mentais ([DSM-5]; APA, 2013) o autismo está incluído no diagnóstico Transtorno de Espectro Autista e como critérios diagnósticos são considerados a comunicação e interação social da criança, além de estereotipias de comportamento, que se apresentam antes dos três anos de idade. Apesar de o autismo contar com indicadores para seu diagnóstico, com sinais e sintomas peculiares a esse transtorno, as mães de crianças com autismo podem enfrentar dificuldades para obterem a confirmação diagnóstica de seu filho, custando a elas a peregrinação por diversos serviços e profissionais de saúde (Schmidt, 2004; Ebertb, Lorenzinic, \& Silva, 2015). Geralmente, são as mães que identificam algum problema, buscam o tratamento, acompanham seus filhos, tornam-se responsáveis pela administração das prescrições médicas e precisam enfrentar e manejar as reações da criança em 
seu dia a dia (Schmidt \& Bosa, 2007; Smeha \& Cezar, 2011), mesmo que toda a família sofra com alterações no cotidiano, que precisa ser ajustado às necessidades da criança com autismo (Minatel \& Matsukura, 2014).

Essas mães passam por um processo que vai desde a resistência inicial até em perceber a diferença e afirmá-la para si, visualizando o contraste existente entre o filho sonhado e o filho real e entendendo que essa criança, em decorrência de suas limitações, não poderá ser conforme ela esperava (Smeha \& Cezar, 2011). Além disso, esse contraste pode evidenciar-se ainda mais pela especificidade de demanda da criança com autismo, como dificuldades na realização de tarefas próprias de sua fase de desenvolvimento, com aumento de seu nível de dependência, impondo maiores exigências às mães (Sifuente \& Bosa, 2010).

Em face da intensa demanda de cuidados, essas mães têm que redimensionar as expectativas quanto ao futuro de seu filho com autismo e quanto ao próprio futuro. Os encargos gerados pelos cuidados com essa criança podem gerar perdas e empobrecimento de sua vida social, afetiva e profissional. Verifica-se que as mães de crianças com autismo tendem a renunciar à carreira profissional, à vida social e às relações afetivas em prol dos cuidados maternos (Smeha \& Cezar, 2011).

Diante das situações vivenciadas, dos encargos decorrentes das demandas dessas crianças, os níveis de depressão são elevados entre mães de crianças com autismo (Sanini, Brum, \& Bosa, 2010; Piovesan, Scortegagna, \& Marchi, 2015), e estudos apontam a importância de redes de suporte social entre ações promotoras e preventivas em relação à saúde mental dessa mãe (Fávero-Nunes \& Santos, 2010; Najarsmeha \& Cezar, 2011; Zanatta, Guimarães, Ferraz, \& Motta, 2014), além da importância do apoio do profissional de saúde para que elas possam lidar de uma maneira mais adequada com as situações geradoras de estresse
(Schmidt \& Bosa, 2007). Dessa forma, segundo Meimes, Saldanha, \& Bosa (2015), o impacto do autismo pode ser amenizado quando mediado por uma rede de apoio social, familiar, por estratégias efetivas de enfrentamento e pela qualidade do sistema de saúde.

Nesse sentido, aponta-se a importância de contribuir na qualificação dos profissionais envolvidos com o cuidado dessas mães, da rede de apoio, no sentido de promover a reflexão sobre os fatores envolvidos em seu cotidiano, além de aspectos subjetivos da relação mãe-filho com autismo. Assim, o objetivo deste estudo é compreender a vivência de mães de crianças com autismo, isto é, compreender os significados atribuídos aos acontecimentos vividos a partir do ser mãe de criança com autismo e discutir diferentes aspectos dessas experiências com base nos discursos dessas mães e na literatura sobre o tema.

\section{Método}

\section{Participantes}

Participaram da pesquisa, seis mães de crianças com autismo. As mulheres entrevistadas deviam satisfazer os seguintes critérios de inclusão: ser mãe de criança com diagnóstico de autismo e ter vontade e possibilidade de colaborar com o estudo. As participantes tinham idade média de 35 anos $(D P=5,92)$, todas elas pertencentes à classe socioeconômica média, três delas com nível de estudo superior e três delas com nível médio. A idade média das crianças com autismo, filhos das participantes era de cinco anos $(D P=2,96)$, conforme dados apresentados a seguir na Tabela 1.

Das participantes citadas, três tinham emprego no mercado formal de trabalho e, com exceção de uma delas, todas eram casadas. Além do filho com autismo, apenas duas tinham outros filhos, sendo a criança com autismo a primogênita em ambos os casos.

Tabela 1

Dados dos Participantes

\begin{tabular}{lccccc}
\hline Participante & Idade & Escolaridade & Ocupação & Estado civil & Outros filhos \\
\hline M1 & 42 & Superior & Psicopedagoga & casada & 3 \\
M2 & 42 & Superior & Não trabalha & casada & 1 \\
M3 & 30 & Ensino Médio & Funcionária pública & separada & 0 \\
M4 & 31 & Ensino Médio & Atendente & casada & 0 \\
M5 & 37 & Superior & Não trabalha & casada & 0 \\
M6 & 26 & Ensino Médio & Não trabalha & casada & 0 \\
\hline
\end{tabular}




\section{Instrumento}

Para coleta de dados, foram realizadas entrevistas com mães de crianças com autismo. O modo como foram conduzidas as entrevistas, nesse trabalho, classificam-nas segundo o tipo semiestruturada ou semidirigida de questões abertas (Turato, 2008). Para abordagem de cada tópico uma ou mais perguntas foram direcionadas às mães.

Os tópicos abordados com as mães, de forma geral, tiveram como referência questões relacionadas ao/às: impacto do diagnóstico de autismo; cotidiano vivido, partilhado com a criança com autismo; atividades do dia a dia realizada por essa mãe; impasses enfrentados no dia a dia resultante da convivência com o filho com autismo.

\section{Procedimentos}

Tendo em vista a população estudada, na realização da coleta de dados foram seguidas as diretrizes e normas para pesquisas envolvendo seres humanos, do Conselho Nacional de Saúde. O projeto foi submetido ao CEP do Centro de Ciências da Saúde da Universidade Federal do Espírito Santo e aprovado em 23 de julho de 2014, sob parecer n. ${ }^{\circ} 730.112$.

A amostra foi intencional, utilizando a técnica Bola de neve (Patton, 1990) para garantir o acesso a essas mulheres. $\mathrm{O}$ método consiste em identificar algumas mulheres elegíveis (egos) e entrevistá-las para saber se aceitam participar. A todas foi solicitado que indicassem os nomes (endereços e número de telefone) de amigas ou mulheres que conhecessem e que são mães de crianças com autismo. Cada mulher indicada foi contatada, informada de quem indicou seu nome e convidada a participar do estudo. A primeira mãe a ser contatada foi indicada por gestora de uma instituição de atenção e cuidado à criança com autismo. $\mathrm{O}$ processo de contato com as mães obedeceu a uma sequência linear, sem intercorrências ou qualquer desistência das mães indicadas para entrevista. Ao mesmo tempo, a indicação de participante feita por outra participante, garantiu certo sigilo do processo da pesquisa, ficando restrito a pequeno grupo de mulheres, não acontecendo de outras mães se oferecerem para participarem da pesquisa.

As entrevistas foram realizadas em local de preferência das participantes, desde que se conseguisse manter a privacidade do processo de coleta. Cinco das entrevistas foram realizadas em associação de mães de crianças com autismo e uma delas foi realizada em parque da cidade. A condução das entrevistas foi feita em dupla por duas das autoras deste estudo. As pesquisadoras tomaram como referência alguns tópicos que serviram de orientação, com o prévio entendimento dos objetivos de cada pergunta, e algumas vezes pelos entrevistados quando associavam ao assunto geral, uma ordem livre de temas particulares. No entanto, o foco do estudo esteve presente no decorrer das entrevistas, limitando as participantes a responderem dentro de um campo associativo bastante definido e previamente delimitado pelas pesquisadoras, conforme orientações de Manzini (2004)

Cada entrevista durou em média quarenta minutos, e as sessões foram gravadas em arquivos digitais de áudio e posteriormente transcritas. A transcrição das entrevistas foi feita pelas autoras deste estudo e fez parte de uma primeira leitura do material, dentre outras cinco leituras feitas posteriormente, no processo de análise dos dados.

$\mathrm{O}$ número de participantes foi determinado pelo critério de saturação. Segundo Fontanela, Ricas e Turato (2008), a avaliação da saturação de uma amostra se dá por um processo contínuo de análise dos dados, começado já no início do processo da coleta. Assim, concomitante à coleta de dados foi feita uma análise preliminar deles, tendo em vista os objetivos da pesquisa, buscando o momento em que pouco de substancialmente novo aparecesse.

O tratamento do material, a sua codificação, deu-se por intermédio da análise de conteúdo (Bardin, 1979). A proposta deste trabalho foi fazer a discussão/ interpretação dos resultados e, por isso, a escolha por esse procedimento de tratamento/análise se deu por permitir discutir/inferir a partir dos dados trabalhados. Há várias maneiras para analisar conteúdos de materiais de pesquisa, esta foi trabalhada na modalidade de análise temática. Esta "procura nas expressões verbais ou textuais os temas gerais recorrentes que fazem a sua aparição no interior de vários conteúdos mais concretos" (Turato, 2008, p. 442). Tendo em vista que esse estudo não pressupunha uma análise quantitativa, as categorias foram delineadas, não necessariamente pela repetição de falas, mas também pela relevância dos relatos no encaminhamento das discussões.

\section{Resultados e Discussão}

Os dados analisados, conforme apresentados na Tabela 2, partiram do estudo de um eixo temático que, a partir da análise do discurso das entrevistas semiestruturadas com as mães de crianças com autismo, foram encontradas regularidades discursivas que delinearam 
três temas. Desses temas, foram configuradas quatro categorias conforme apresentado na Tabela 2.

$\mathrm{Na}$ Tabela 2, estão indicados os temas principais delineados pelo núcleo de sentido do conteúdo das falas das participantes. A partir dos temas, foram identificadas quatro categorias e seus respectivos subtemas.

$\mathrm{Na}$ apresentação dos trechos dos relatos dos participantes, os nomes das mães foram omitidos e substituídos pela letra $\mathrm{M}$. Os números correspondem à identificação numérica de cada participante.

\section{Categoria 1- "Ninguém quer ter um filho autista"}

Segundo Schorn (2002), o casal constrói a imagem do seu filho durante a gestação e, às vezes, até muito antes. São suas próprias identificações, aspirações e frustrações que constroem essa imagem do filho esperado. Porém, nem sempre as expectativas correspondem à realidade:

Eu já fiquei chocada, tive que fažer cesárea. Eu não queria. Aí já foi complicado. Aí você vai caminhando, esperando o menino se desenvolver, do que eles dizem tempo normal. (M1)

No relato de M1, está presente o sentimento de decepção em relação ao nascimento e desenvolvimento de seu filho, ressaltando também o ideal dentro do padrão de normalidade em relação à faixa etária da criança. Esses dados evidenciam e confirmam os estudos de Smeha e Cezar (2011) para quem o contraste entre o filho sonhado e o filho real, na situação do autismo, dá-se em decorrência das limitações da criança no decorrer do seu desenvolvimento.

Nesse sentido, a diferença apresentada pelo filho de M1 e de muitas crianças com autismo não são prontamente notadas pelas mães e familiares, ao contrário de mães que confrontam bruscamente o filho imaginado com a realidade de um filho com deficiência (Teixeira $\&$ Moraes, 2008). No que diz respeito às crianças com autismo, na maioria das vezes, nascem com características físicas e cognitivas sem anormalidades aparentes, levando a mãe a jamais imaginar qualquer transtorno, No entanto, mesmo quando a diferença da criança com autismo em relação às crianças típicas vai se evidenciando, a reação da mãe pode ser no sentido de evitar essa realidade, conforme exemplifica relato de M6:

Poucos, poucos sintomas. São leves, mas eu tava "mununito" cansada. Eu ainda tô muito cansada. Então, eu não consegui reparar, para falar a verdade. [...] Eu não consegui reparar nada diferente, mas também por causa do cansaço $A$ única coisa que eu via que não era normal era o men cansaço. (M6)

$O$ fato de não perceber a diferença apresentada por seu filho, aliado ao cansaço, pode ser resultado de um processo de negação da realidade que consiste em um mecanismo de defesa ou coping (APA, 2013). Ribeiro e Rodrigues (2004) apontam que tanto os mecanismos de defesa, como as estratégias de coping, podem ajudar a reduzir os efeitos de emoções fortes provocadas por estressores. Esse dado vai ao encontro da afirmação de

Tabela 2

Resultados

\begin{tabular}{|c|c|c|c|}
\hline Eixo temático & & emas & Sub temas \\
\hline \multirow{4}{*}{$\begin{array}{l}\text { Vivência de mães } \\
\text { de criança com } \\
\text { autismo }\end{array}$} & $\begin{array}{l}\text { Impacto do diagnóstico } \\
\text { de autismo }\end{array}$ & $\begin{array}{l}\text { Categoria1: "Ninguém quer } \\
\text { ter um filho autista" }\end{array}$ & $\begin{array}{l}\text { - Filho imaginado X filho real } \\
\text { - Necessidade do diagnóstico } \\
\text { - Desestabilização } \\
\text { - Reajuste no cotidiano } \\
\text { - Sobrecarga/ estresse }\end{array}$ \\
\hline & Suporte Social & $\begin{array}{l}\text { Categoria 2: "A rejeição } \\
\text { começa em casa" }\end{array}$ & $\begin{array}{l}\text { - Prejuízo na relação coparental } \\
\text { - Isolamento do contexto familiar } \\
\text { - Exclusão das relações/contextos } \\
\text { sociais }\end{array}$ \\
\hline & & $\begin{array}{l}\text { Categoria 3: "Irmãs de } \\
\text { alma" }\end{array}$ & $\begin{array}{l}\text { - Redes sociais de apoio } \\
\text { - Grupo de mães de crianças com } \\
\text { autismo }\end{array}$ \\
\hline & $\begin{array}{l}\text { Ser mulher e mãe de } \\
\text { criança com autismo }\end{array}$ & $\begin{array}{l}\text { Categoria 4: "Me arrumar } \\
\text { pra que?" }\end{array}$ & $\begin{array}{l}\text { - Dedicação exclusiva ao papel de } \\
\text { mãe }\end{array}$ \\
\hline
\end{tabular}


Marques. (1995) de que as mães, ao se depararem com a perda do filho imaginado por elas, podem ser bastante atingidas emocionalmente. Logo, pode apresentar tristeza, sentimento de frustração e negação. Os autores apontam ainda que esses sentimentos possam alterar a relação mãe/criança (Santos, 2009; Badinter, 1985), o que pode ser exemplificado no relato de M3:

[...] mas é uma realidade que não, que a gente tem amor pelos nossos filhos. Eu amo ele, né? E eu tenho que sacar força de onde não existe pra dar amor pra ele Mesmo, mesmo naqueles piores momentos. (M3)

O relato de M3 mostra uma realidade bastante pesarosa com a qual deve lidar, inclusive utilizando de esforço para que o amor ao seu filho sobreponha às dificuldades. Esse esforço para amar o filho contrapõe-se à ideia de amor materno difundido e compartilhado socialmente, como amor natural, inato, instintivo e incondicional. Badinter (1985) apoia-se na perspectiva de que a maternidade é construída e não instintiva, assim como o amor materno. O "sacar forças" relatado por M3 remete a certa insistência em um amor "natural", que entra em choque com sua vivência e seu sofrimento, opondo-se ao padrão de amor materno e de mãe cultuado socialmente.

Diferente de M3 que mostra certo conflito por ter que se esforçar para dar amor ao filho, o relato abaixo de M2 mostra questionamento a respeito da experiência de ter um filho com autismo, parecendo flexibilizar o padrão materno construído socialmente:

Querer ter um filho autista, ninguém quer! Quem falar se eu tivesse de ter, eu queria ter é mentira! Eu acho que é mentira. Ninguém quer ter doença, ninguém quer ter um filho autista, ninguém quer ter um filho especial, ninguém quer gente... Ninguém quer cair num buraco, não é? Ninguém quer! (M2)

Para M2, a vivência de ser mãe de uma criança autista é comparada a cair em um buraco. A imagem "cair no buraco" nos leva a pensar em vazio, sofrimento inesperado, problema grave. Consultando o dicionário (Houaiss, 2004), a palavra buraco traz como significado ferimento profundo, que parece ser a experiência de M2 ao deparar-se com o autismo de seu filho. O mesmo dicionário traz outros significados, como espaço vazio, sentimento de falta ou de perda de alguma coisa ou pessoa. Segundo essa fala, o buraco pode ser significar um vazio deixado pelo filho idealizado e o ter que lidar com uma realidade impensada, incalculada e, portanto, fora de controle. Essa vivência pode anteceder ao diagnóstico de autismo, quando a mãe se vê diante do comportamento diferente do filho, diante de dúvidas em como agir, diante da falta de compreensão da situação.

$\mathrm{Na}$ busca pelo tratamento, pelo controle da situação, surge também, por parte da família e, mais especificamente da mãe, a busca de sentido, de significado daquilo que está causando, na maioria das vezes, turbulência ao cotidiano dessas pessoas (Constantinidis, 2011). A necessidade de compreender essa vivência vem formulada, por essas mães, pelo pedido de um diagnóstico, que nem sempre é fácil de ser obtido:

Recorri a vários profissionais e nenbum deles dava credibilidade para aquilo que eu falava. Ah, não... Mas cada criança tem seu tempo. Você está comparando um filho no outro [...]. (M1)

[...] e eu sempre questionando o pediatra e tal, e ele sempre falou para mim que era normal, normal. Eu levava muito ele no médico. Eu sempre achava muito estranho. (M3)

Eu comecei a ler, en comecei a pesquisar porque ninguém é capaz de diagnosticar o autismo dele, só en [...] O que ajudou foi isso mesmo, as minhas pesquisas e o meu registro. As pesquisas que en fir foi o que ajudou no diagnóstico senão a médica ia ficar até hoje achando o que ele era on não era. (M5)

Essa busca incessante por um diagnóstico conforme ilustra os relatos de M1, M3 e M5 é a busca de um sentido para a situação vivida. A posição dos profissionais é de se eximirem da resposta esperada pelas mães, ou seja, o diagnóstico. Segundo Constantinidis (2011), o enquadre do comportamento diferente em um diagnóstico, pode ser um norteador para o familiar que, sem ele, pode sentir-se à deriva com suas experiências e alienado quanto às suas ações. Para a autora, enquadrar a diferença da criança em um diagnóstico é a forma dos familiares lidarem com a situação turbulenta em que se encontram. O diagnóstico psicopatológico é um lugar em que a diferença que preocupa e/ou incomoda passa a ocupar, podendo ser referida com um nome. Deixa a categoria de inominável para a concretude de um código a ser compartilhado, dando garantia de doença ao comportamento da criança, assim como pode ser observado no relato das mães:

[...] porque eu meio que me sinto assim, não é culpada, mas eu me sinto responsável se ele fizer uma bagunça, porque agora eu sei que ele é autista, antes eu não sabia. (M6) 
Ai ele falou, pois é en fecho o diagnóstico dele agora. Ele é autista clássico grave. Ele é autista clássico. Ele tem todas as características. Ai eu falei assim: "é isso o que en quero. Eu vou chorar, chorar tudo o que eu tenho direito, mas é isso o que en quero. Eu quero fechar o diagnóstico”. (M2)

O diagnóstico traz a clareza da situação do filho e norteia as mães em suas ações com a criança, conforme os relatos acima. Esse resultado corrobora o estudo de Schmidt (2004) que aponta que, ao aceitar a condição do filho como autismo, a mãe passa a submeter-se às exigências da condição da criança, tornando essa aceitação algo positivo ou negativo, dependendo do contexto em que vivem os indivíduos envolvidos. Saber o diagnóstico orienta essa mãe em questões essenciais de comportamento com o filho, como saber o modo de agir, falar, portar-se com ele. No entanto, o fato de haver a busca pelo diagnóstico, não significa que não haverá sofrimento ao recebê-lo:

Ai... é muito difícil, muito cansativo. No comeco, no primeiro mês, eu passei o primeiro mês só chorando. Eu olhava para o céu e eu chorava. Eu olhava para um passarinho e chorava. Mas eu me lembro muito bem assim dentro de casa. Eu ia para a janela, olhava para o céu e ficava chorando. Eu estava no carro, olhava para o céu e eu ficava chorando. Hoje em dia eu choro um pouco menos, né. (M6)

Podemos observar pela fala de M6 que o diagnóstico foi disparador de uma desestabilização emocional e que, antes mesmo de qualquer readaptação no seu cotidiano, ela experimenta uma profunda tristeza que se expressa por meio do choro constante. Esse impacto vivenciado pelas mães de crianças com autismo em decorrência do diagnóstico, assim como vivenciado por M6, é pouco explorado na produção científica nacional, conforme aponta Fávero-Nunes e Santos (2010), sendo pesquisada com maior frequência a depressão associada aos familiares, incluindo cônjuges e filhos. Diante disso, parte-se da premissa que o impacto do diagnóstico não se localiza apenas na mãe, torna-se um marco importante e gerador de desestabilização familiar e a negociação de novos papéis, faz parte da busca pela reacomodação da família frente à nova realidade. Nesse sentido, Sprovieri e Assumpção Jr. (2001) afirmam que o transtorno traz, além das consequências para a pessoa em sofrimento psíquico, influência na situação social de todo o grupo familiar e pode gerar um rompimento nas atividades sociais normais. Isso parece claro nos relatos das vivências dessas mães:
Não diria que seja ser um refém, mas é uma mudança radical [..] Tudo mudou. Na verdade tudo mudou, a rotina de casa mudou, estrutura dos móveis, a forma que ele chegava e largava uma mochila, uma bolsa. Então mudou a vida de todo mundo[...] Eu não vou a show na praia. Não vou em nada que tenha barulho. Não saio à noite. (M1)

O relato de M1 vai ao encontro dos resultados dos estudos de Minatel e Matsukura (2014) que apontam que todo o cotidiano das famílias fica voltado para a criança ou o adolescente com autismo. A dinâmica domiciliar, as atividades diárias, as rotinas de horário, independentemente da singularidade de cada integrante da família, são alteradas. Todos os horários e rotinas são modificados para poder dar o suporte e o cuidado necessário ao autista. Para a criança com autismo, as dificuldades nas relações sociais podem ocasionar problemas que refletem no cotidiano da mãe, já ela que passa a viver em função das suas exigências e permanente dependência, exemplificado na fala de M4:

Mas eu só conseguia trabalhar e voltar para casa. O resto não dava para fazer nada porque, quando saía, dava problema. (M4)

A gente tem evitado muitas pessoas. Então, são poucas as coisas que a gente consegue fazer. A maioria das coisas são frustradas, né. Quando a gente chega, ele começa a ficar nervoso, gritar, chorar... Ou a gente volta e desiste de ir até o final ou a gente nem vai. É complicado. (M6)

De acordo com Zanatta, Guimarães, Ferraz e Motta (2014), o autismo acarreta mudanças no cotidiano familiar, porém, a mudança maior é no cotidiano das mães. Ao observarem a dependência do filho, as mães passam a dedicar-se totalmente a eles. Essa dedicação traz sobrecarga física e emocional, tanto com os cuidados gerais do filho com autismo como também com todas as outras tarefas do dia, como os cuidados com a casa, atenção aos outros integrantes da família e, ainda, o seu emprego, conforme relatado por M6 e M2:

É bem frustrante, mas, por enquanto, eu não tenho outra opção porque, para eu trabalhar, botar ele no integral não pode porque ele tem que vir fazer as terapias. (M6)

Deixei de trabalhar. Eu amava o que eu fazia. Sempre gostei de dar aula. Só que meu filho era muito difícil, empregada não parava. Como você sai pra trabalhar e fica o dia inteiro fora e com um menino que escalava armário e fazia de tudo? 
Empregada nenhuma ficava. Então eu tive que fazer isso. É triste? É muito triste. Não pense você que sou feliz.por isso, não sou. Não sou mesmo. (M2)

Diante dessa situação, os resultados indicam que a dedicação aos cuidados do filho com autismo requer de algumas mães o abandono de seus empregos. Esse dado corrobora o estudo de Meimes et al. (2015) que indica que a abdicação à vida profissional é um dos resultados do impacto negativo do diagnóstico do autismo na vida social da mãe.

Algumas mães, no entanto, resistem a abdicar a vida profissional e tentam conciliar a profissão, as horas de trabalho no emprego, com os cuidados com o filho com autismo. Essa opção torna-se um fardo, uma tarefa que, pela sobrecarga com a dupla jornada e o encargo com o filho com autismo, pode trazer consequências à saúde dessa mãe, como relata M6:

Eu dormia duas horas por noite. E no outro dia eu tinha que trabalhar. Você imagina. Você encarar uma quadra com 35 alunos cada turma, sem dormir. Ai eu chegava em casa, a babá já estava na porta entregando o bebê para ir embora. Então eu desmaiava na quadra. Eu vivia em pronto socorro. Tive hipoglicemia. Tanto é que 42 anos eu já tive menopausa, catarata. Eu antecipei todas as doenças da $3^{\circ}$ idade. Eu tive tudo antes, precoce. (M 6)

Estudos apontam que as mães de crianças com autismo são propensas ao estresse (Lecavalier, Leone, \& Wiltz, 2006; McDonald, Poertner, \& Pierpont, 1999). O estresse da mãe da criança com autismo está relacionado ao ajustamento realizado por ela nas situações cotidianas. Segundo análise de Fávero e Santos (2005), a gravidade do transtorno da criança, o lócus de controle percebido pela mãe e o suporte social, são fatores significantes para o ajustamento dessa mãe. Assim, quando a severidade dos sintomas do autismo for menor e maior for o suporte social das mães, mais fácil será a para a ela a criação de seu filho com autismo.

\section{Categoria 2- "A rejeição começa em casa"}

No cotidiano conturbado enfrentado, no cuidado com o filho e na relação com o meio social, diante de preconceitos e estigmas decorrentes do autismo, o apoio das pessoas próximas a essas mães nem sempre se faz presente. Conforme relatado por M3, pode acontecer dos pais das crianças com autismo não aceitarem o diagnóstico do filho e se ausentarem de suas responsabilidades:

\begin{abstract}
Eu não tive muito tempo para raciocinar, né, mas para mim o pior de tudo do diagnóstico foi o pai não aceitar, né. O pai dele nunca aceitou. Agredia muito ele. [...] Eu era casada, mas o pai nunca aceitou levar o J. em tratamento, nunca. E isso eu tive que bater de frente com ele porque ele não aceitava que o filho dele frequentasse uma APAE. Ele nunca aceitou, ele nunca aceitou. (M3)
\end{abstract}

Nesse caso, ao invés da mãe encontrar apoio e ajuda com o companheiro, encontra uma dificuldade a mais a ter que resolver. Como foi visto, no exemplo de M3, nem sempre a presença do pai garante um suporte a essa mãe. Pode haver diferenças entre os pais quanto à aceitação do filho e da condição do autismo, o que pode resultar em prejuízos na relação coparental. A relação coparental é aquela que se estabelece por meio de acordo mútuo ou normas sociais, a responsabilidade conjunta pelo bem-estar de determinada criança (Feinberg, 2002). A dificuldade do pai em aceitar a condição do filho, como é o caso de M3, é um dos motivos da sobrecarga da mãe na divisão do trabalho entre o casal, nos cuidados com o filho com autismo, conforme aponta estudo de Sifuentes e Bosa (2010).

Além do pai, outras pessoas podem compor o suporte para a mãe, na realização de suas atividades. Sanini, Brum e Bosa (2010) reforçam a importância do pai ou outros adulto, além do uso de suporte social para auxílio a essas mães. As redes de suporte são elementos fundamentais para a diminuição da sobrecarga das mães e também pontos importantes para realização de atividades sociais, devido à dependência da criança com autismo (Andrade \& Teodoro, 2012). A família é um elemento importante nesse suporte, mas nem sempre disponível para essa mãe:

\footnotetext{
Agora, já a família do meu marido, eles já, assim, deletaram, sabe?! Não são de visitar. É como se não existisse. Não tem raiva, não discrimina, mas também não abraçam a causa. É difícil! (M2)
}

As primas do meu marido, que viviam querendo ficar com o neném, passear, que não sei o que, sumiram. A rejeição começa em casa. (M6)

Em decorrência disso, pode faltar apoio e ajuda familiar no cotidiano dessas mães. O auxílio de familiares, que ajudaria a mãe dar conta dos encargos no cuidados com seu filho com autismo, pode estar ausente nessa situação. Mas, assim como sofrem certo isolamento no contexto familiar, as mães sofrem com a exclusão extra-familiar a que são expostos seus filhos 
com autismo. Essas crianças deixam de ser convidadas para eventos, por exemplo, e são excluídas das relações sociais:

Em festa, nunca é convidado. $\mathrm{R}$, ele tá na $3^{\circ}$ série, terceiro ano e nunca foi convidado para o aniversário dos colegas. Eles não convidam, mesmo. É horrivel, né! Não convidam. É triste isso. Isso me deixa triste (choro). (M1)

Minhas melhores amigas nunca me chamaram para ir na casa delas. Na verdade, en fui uma vez depois que en voltei para o Brasil e nunca mais fui convidada. (M3)

Devido às diversas situações enfrentadas, essas mães isolam-se do seu contexto social e têm seu cotidiano alterado. Deixam de visitar amigos, parentes e relutam em pedir ajuda.

\section{Categoria 3- "Irmãs de alma"}

Estudo de Zanatta et al. (2014) aponta que essas mães sentem necessidade de serem ouvidas e confortadas, porém, nem sempre encontram a ajuda necessária. Os profissionais, por meio de apoio e mediação, podem minimizar o impacto. Contudo, a relação social da mãe e da criança com autismo não pode ser limitada ao âmbito do ambiente de atendimentos por esses profissionais. A rede social precisa ser expandida para outros meios para que essa mãe possa contar com apoio e suporte que necessita.

As redes sociais de apoio vêm para sustentar e colaborar com o impacto gerado em virtude dos encargos dessas mães com o cuidado do filho (Zanatta et al., 2014). No entanto, no cotidiano com a criança com autismo, como vimos, nem sempre as mães tem esse suporte.

Todo final de semana eu tenho cuidadora, então eu falo, eu não preciso de mais nada. Tem mãe aqui que não tem 0 direito de ir ao banheiro. Ela leva o menino no banbeiro, porque se ela for ao banheiro e fechar a porta, ele bate na porta. Então, eu me sinto tão mesquinha abrindo a boca para reclamar de alguma coisa, Então você dá valor... que, se eu for abrir a boca para reclamar de não ir ao salão todo final de semana, eu me sinto assim, espiritualmente tão pobre. Então assim, eu me acho muito privilegiada diante das mães daqui (M2).

Essas mães precisam de apoio e ajuda, durante a trajetória. $\mathrm{O}$ auxílio de outras pessoas sejam cuidadores e/ou familiares, como também instituições, auxiliam as mães na sobrecarga de cuidados com seus filhos.
Nota-se na fala de algumas mães que as redes de apoio/ suporte social desempenham esse papel, auxiliando-as a viver melhor com a situação. A rede social é caracterizada por relações significativas estabelecidas entre ela e outras pessoas ou instituições, que oferecem suporte desde emocional até financeiro. Nota-se que esse papel é feito por grupo de mães pertencentes à associação de familiares de crianças com autismo:

Para você ter uma ideia, eu tenho um grupo de mães de autismo. Aquele grupo foi um... Assim, elas viraram irmãs porque gente que vivia presa dentro de casa porque os amigos se afastaram, além de não convidar, ainda não frequenta a sua casa. Então elas viviam isoladas [...] As meninas viraram irmãs de alma agora. Só quem tem que entende, né (M3).

O que veio agregar muito valor pra gente foi a associação da Amaes. Percebi assim um divisor de águas. É como se fosse uma tribo. Você se ach a diante daquilo, vai vendo as mesmas realidades. Então, ai você começa a faz̧er festas, começa a fazer eventos, mas com a sua realidade [...] (M4).

Pelos relatos, de M3 e M1 nesse grupo, há a identificação dos participantes pela dor, pelo sofrimento e a partir daí a criação de uma rede de suporte entre elas. Ser uma mãe de criança com autismo e tudo que isso envolve, é condição de pertença ao grupo e o sofrimento serve de aliança para elas. Nessa condição, ao invés de estagnadas, conformadas com os encargos e sofrimento, o grupo de mães de crianças com autismo opera no sentido de estar implicado com sua dor que faz parte da vivência dessas mulheres que, juntas, podem buscar abertura de linhas de fuga desse lugar da queixa, da dor e se implicar, responder as situações que geram sofrimento.

\section{Categoria 4- "Me arrumar para quê?"}

A mãe toma para si a maior carga de responsabilidade no cuidado do filho. É esperado da mulher que ela seja cuidadora por excelência e, geralmente, é ela quem assume a responsabilidade de se tornar cuidadora principal. Essa é expectativa social de desempenho ligada a mulher. Em relação à imagem da mulher, esta é identificada, de forma acrítica, ao afeto, a maternidade e ao amor incondicional (Gutierrez \& Minayo, 2009). Em relação às mães de crianças com autismo, a maternidade ocupa todo o tempo dessas mulheres, não sobrando tempo para elas mesmas, para outras funções e realizações, conforme exemplifica os seguintes relatos: 
Cuidar de mim é a última coisa que eu penso (M6).

E assim, até hoje, né? Olha os meus cabelinhos brancos aqui (risos), por praticidade en vou deixar. Vou inventar um negócio para disfargar, mas vou gastar tempo com tinta não (risos). Vou ver uma coisa mais prática. Então, assim, é difícil mesmo porque para você se cuidar precisa de tempo. (M4)

Eu saio com ele. Pra sair com criança, você tem que sair de mochila. A mochila te deixa com os braços soltos. Com criança autista você tem que ter tudo na bolsa. Você vira mocbileira. Amarro meu cabelo, procuro andar sem brinco, Se ele der alguma crise, ele não arranca men brinco. Ando com roupas que têm bolso para ir colocando tudo no bolso (M5).

Conforme relato das mães, verifica-se que estas dedicam tempo integral do seu dia ao filho, sendo essa a prioridade em sua rotina diária. Esses resultados corroboram o estudo de Nunes (2010), que aponta que a mãe da criança com autismo dedica todo seu tempo e sua energia para cuidar do filho, acrescentando que há ainda o sacrifício enquanto mulher.

Você não consegue este tempo pra se cuidar. O cuidado com a gente cai em $80 \%$ [...]. Se for pra marcar num salão, quem vai ficar com ele? Se for pra sentar em casa e fazer, como faz? Não dá. Até para fazer uma refeição fica difícil. Às vezes, o menino está até calmo, mas você não está animada. Tem isso também. Vou me arrumar pra quê (M5)?

Quase não sobra espaço para isso mesmo não, é difícil. Eu costumo o que a terapenta pede pra pelo menos assim reservar um tempo de qualidade pra mim, pra esta questão de fazer uma unha, de sair com uma colega pra alguma coisa, ou fazer um cabelo e tal. (M1)

Segundo o relato da mãe 5, a mãe não vê qual a finalidade em se arrumar, cuidar de si mesma. Parece não ter referências fora do seu mundo, do seu cotidiano de mãe de criança com autismo. Ser mãe sobrepõe-se ao ser mulher (Smeha, \& Cezar, 2011). Arrumar-se para si, para seu companheiro e para suas atividades sociais ficam em segundo plano.

[...] Mas aí en falo, meu marido fala: "Ah, por que você não vai lá no salão, faz. não sei o quê, alguma coisa que você gosta?" Ai eu falo: "Uai, pra quê?? Eu vou pra onde?" (M6)

Ele [o marido] tenta, me chama pra sair, pra ir beber um chope, pegar um cineminha, mas não dá... Não dá a mínima vontade. É só canseira, mesmo (M4).
A tentativa do marido, de resgatar outro lugar para a mulher, torna-se frustrada por ela estar totalmente submergida no mundo de seu filho com autismo e com sua função materna, não abrindo espaço para outros prazeres, para a sexualidade. Nesse cotidiano compartilhado com o filho com autismo, as mães perdem sua própria história e passam a viver a história do filho e não veem sentido na tentativa de resgate de outras possibilidades em ser mulher, realizadas por seus parceiros. O arrumar-se, no caso, seria a abertura para outros encontros possíveis, para uma interação com o mundo que essa mãe vê como desnecessária.

As redes de suporte social são representadas, neste estudo, exclusivamente por grupo de mães de crianças com autismo. Pode-se pensar que essa mãe, ao se identificar somente como mãe de autista, não vendo sentido em outras possibilidades de existência - "me arrumar pra quê?" - e sentir-se amparada somente em grupo de mães com esse mesmo perfil, possa restringir seu universo, em um movimento que a coloca isolada do mundo, tal qual seu filho com autismo.

\section{Considerações Finais}

Por meio dos achados apresentados, acredita-se que este estudo tenha contribuído para a ampliação da literatura concernente à atenção à mãe da criança com autismo. No entanto, é importante destacar que, pelo fato do contato inicial com as participantes, pelo método bola de neve, ter partido de indicação de gestor de uma instituição, pode ter restringido o grupo de sujeitos da pesquisa, resultando em pouca variabilidade do discurso, o que pode ser um viés deste estudo.

Destaca-se, como achado deste estudo, a importância do diagnóstico como norteador de ações para essas mães. Esse resultado aponta a resistência de profissionais que evitam dar o diagnóstico, em conversar e orientar as mães nesse sentido. Espera-se com esse resultado fomentar pesquisas futuras que possam explorar as razões dos profissionais para evitarem fornecer o diagnóstico para as mães da criança com autismo, assim como estudar a relação entre profissionais de saúde mental e as referidas mães.

Outro resultado a ser destacado é a presença da figura paterna, não como parceiro no cotidiano com o filho com autismo, mas negativamente, como mais um familiar que pode rejeitar o autismo. No entanto, esse pai aparece também quando tenta resgatar a identidade feminina dessa mãe, perdida quando esta assume o ser mãe de seu filho com autismo. É interessante notar que 
o papel do pai para além da coparentalidade é pouco explorado nos estudos sobre autismo. Nesse sentido, estudos futuros sobre o processo de subjetivação do pai da criança com autismo mostram-se como relevantes.

\section{Referências}

American Psychiatric Association. (2013). Diagnostic and statistical manual of mental disorders (5th ed.). Washington, DC: Author.

Andrade, A. A., \& Teodoro, M. L. M. (2012). Família e autismo: Uma revisão de Literatura. Contextos Clínicos, 5(2), 133-142. Recuperado de http://revistas. unisinos.br/index.php/contextosclinicos/article/ view/ctc.2012.52.07

Badinter, E. (1985). Um amor conquistado: o mito do amor materno. Rio de Janeiro: Nova Fronteira.

Bardin, L. (1979) Análise de conteúdo. Lisboa: Edições 70.

Constantinidis, T. C. (2011). Familiares de pessoas com sofrimento psíquico e profissionais de saúde mental: Encontros e desencontros (Tese de doutorado). Vitória ES: Programa de Pós Graduação em Psicologia da Universidade Federal do Espírito Santo- UFES.

Ebertb, M., Lorenzinic, E., \& Silva, F. E. (2015). Mães de crianças com transtorno autístico: Percepções e trajetórias. Rev. Gaúcha Enferm. 36(1). 49-55. Recuperado de http://www.seer.ufrgs. br/RevistaGauchadeEnfermagem/article / viewFile/43623/33312

Fávero, A. M., \& Santos, M. D. (2005). Autismo infantil e estresse familiar: Uma revisão sistemática da literatura. Psicologia: Reflexão e Crítica, 18(3), 358-369. Recuperado de http://www.redalyc.org/articulo. oa?id $=18818310$

Fávero-Nunes, A. M., \& Santos, M. D. (2010). Depressão e qualidade de vida em mães de crianças com transtornos invasivos do desenvolvimento. Rev. Latino-Am. Enfermagem, 18(1), 1-9. doi: 10.1590/1518-8345.1074.2668

Feinberg, M. E. (2002). Coparenting and the transition to parenthood: A framework for prevention. Clinical Child and Family. Psychology Review, 5(3), 173-195. doi: 10.1023/A:1019695015110

Fontanella, B. B.; Ricas, J.; \& Turato, E. R. (2008). Amostragem por saturação em pesquisas qualitativas em saúde: contribuições teóricas. Cad. Saúde
Pública, 24(1), 17-27. Disponível: http://www.scielo.br/pdf/csp/v24n1/02

Gutierrez, D. M. D., \& de Souza Minayo, M. C. (2009). Papel da mulher de camadas populares de Manaus na produção de cuidados da saúde. Saúde e Sociedade, 18(4), 707-720. doi: 10.1590/ S0104-12902009000400014

Houaiss, A., \& Villar, M. D. S. (2004). Minidicionário da língua portuguesa. Rio de Janeiro.

Lecavalier, L., Leone, S., \& Wiltz, J. (2006). The impact of behaviour problems on caregiver stress in young people with autism spectrum disorders. Journal of Intellectual Disability Research, 50(3), 172-183. doi: 10.1111/j.1365-2788.2005.00732.x

Manzini, E. J. (2004). Entrevista semiestruturada: Análise de objetivos e de roteiros. Seminário internacional sobre pesquisa e estudos qualitativos, 2, 2004. Bauru: USC, CD-ROM. ISBN: 85-9862301-6. 10p.

Marques, L. P. (1995). O filho sonhado e o filho ideal. Revista Brasileira de Educação Especial, 2(3), 27-36. Recuperado de http://www.abpee.net/ homepageabpee04_06/artigos_em_pdf/revista3numero1pdf/r3_comentario01.pdf

McDonald, T. P., Poertner, J., \& Pierpont, J. (1999). Predicting caregiver stress: An ecological perspective. American Journal of Orthopsychiatry, 69(1), 100. doi: $10.1037 / \mathrm{h} 0080385$

Meimes, M. A., Saldanha, H. C., \& Bosa, C. A (2015). Adaptação materna ao transtorno do espectro autismo: Relações entre crenças, sentimentos e fatores psicossociais. Psico, v. 46, n. 4, pp. 412-422. doi: 10.15448/1980-8623.2015.4.18480

Minatel, M. M., \& Matsukura. T. S. (2014). Famílias de crianças e adolescentes com autismo: Cotidiano e realidade de cuidados em diferentes etapas do desenvolvimento. Revista de Terapia Ocupacional da Universidade de São Paulo, 25(2), 126-34. doi: 10.11606/issn.2238-6149.v25i2p126-134

Najarsmeha, L., \& Cezar, K. P. (2011). A vivência da maternidade de mães de crianças com autismo. Psicologia em Estudo, Maringá, v. 16, n. 1, p. 43-50, jan./ mar. doi: 10.1590/S1413-73722011000100006

Nunes, M. A. F. (2010). Consulta terapêutica com pais de crianças autistas: a interface entre a parentalidade e 
a conjugalidade Tese de doutorado - Universidade de São Paulo.

Patton, M. Q. (1990). Qualitative evaluation and research methods. $2^{a}$ ed. Newbury Park: Sage Publications.

Piovesan, J., Scortegagna, A. S., \& Marchi, B. A. (2015). Qualidade de vida e sintomatologia depressiva em mães de indivíduos com autismo. Psico-USF, v. 20, n. 3, p. 505-515, set./dez. doi: 10.1590/1413-82712015200312

Ribeiro, J. L. P., \& Rodrigues, A. P. (2004). Questões acerca do coping: A propósito do estudo de adaptação do Brief Cope. Recuperado de http:// repositorio.ispa.pt/handle/10400.12/1054

Santos, M. A. (2009). Entre o familiar e o estranbo: Representações sociais de professores sobre o autismo infantil (Dissertação de mestrado). Programa de Pós-graduação em Psicologia da Universidade Federal da Paraíba.

Sanini, C., Brum, M. H. E., \& Bosa, A. C. (2010). Depressão materna e implicações sobre o desenvolvimento infantil do autista. Rev. Bras. Crescimento Desenvolvimento Hum. 20(3) 809-815. Recuperado de http:// pepsic.bvsalud.org/scielo.php?script=sci_arttext\& pid $=$ S0104-12822010000300016

Schorn, M. (2002). Discapacidad, una mirada distinta, una escucha diferente. Buenos Aires: Lugar Editorial.

Schmidt, C. (2004). Estresse, autoeficácia e o contexto de adaptação familiar de mães de portadores de transtornos globais do desenvolvimento. Universidade Federal do Rio Grande do Sul. Instituto de Psicologia. Curso de Pós-Graduação em Psicologia do Desenvolvimento.

Schmidt, C., \& Bosa, C. (2007). Estresse e autoeficácia em mães de pessoas com autismo. Arq. bras. psicol., 59(2), 179-191. Recuperado de http://pepsic.bvsalud.org/pdf/arbp/v59n2/v59n2a08.pdf
Schmidt, C., Dell'aglio, D. D., Bosa, A. C. (2007). Estratégias de coping de mães de portadores de autismo: Lidando com dificuldades e com a emoção. Psicologia: Reflexão e Crítica, 20(1), 124-131. doi: 10.1590/ S0102-79722007000100016

Sifuentes, M., \& Bosa, C. A. (2010). Criando pré-escolares com autismo: Características e desafios da coparentalidade. Psicologia em estudo, 15(3), $477-$ 485. Recuperado de http://www.lume.ufrgs.br/ bitstream/handle/10183/98805/000766091. pdf?sequence $=1$

Smeha, L. N., \& Cezar, P. K. (2011). A vivência da maternidade de mães de crianças com autismo. Psicol. estud., 16(1), 43-50, 2011. Recuperado de http:// www.scielo.br/pdf/pe/v16n1/a06v16n1

Sprovieri, M. H. S., \& Assumpção JR., F. B. (2001). Dinâmica familiar de crianças autistas. Arquivos de Neuropsiquiatria, 59(2), 230-7. Recuperado de http://www.scielo.br/pdf/\%0D/anp/v59n2A/ a16v592a.pdf

Teixeira, L. C., \& Moraes, W. M. S. D. (2008). Implicações subjetivas das vivências da gravidez e do diagnóstico da cardiopatia do filho: Aportes psicanalíticos à saúde da mulher. Mundo Saúde, 32(4), 519-29. Recuperado de http://www.saocamilo-sp. br/pdf/mundo_saude/65/14_Implicacoes_baixa. pdf

Turato, E. R. (2008) Tratado da metodologia da pesquisa clínico-qualitativa. Petrópolis, RJ: Vozes.

Zanatta, E. A., Guimarães, A. N., Ferraz, L., \& Motta, M. G. C. (2014). Cotidiano de famílias que convivem com o autismo infantil. Revista Baiana de Enfermagem, 28(3), 271-282. Recuperado de http://search.proquest.com/openview/b79b6e0325d3dedf7e3a41b dc036d57b/1 ?pq-origsite $=$ gscholar\&cbl $=2040112$

Recebido em: 30/11/2015 Refomulado em: 03/11/2016; 08/02/2017

Aprovado em: 03/03/2017 
Sobre as autoras:

Teresinha Cid Constantinidis é doutora em Psicologia pela Universidade Federal do Espírito Santo - UFES e mestre em Psicologia Social pela USP. Atualmente é professora do Programa de Pós-Graduação em Psicologia da UFES e professora adjunta do Departamento de Terapia Ocupacional da mesma universidade. Sua linha de pesquisa centra-se em Psicologia Social e Saúde, especialmente prática profissional na área da saúde mental, processos de atenção e cuidado aos familiares, reabilitação psicossocial.

E-mail: teracidc@gmail.com

Laila Cristina da Silva é graduada em Terapia Ocupacional pela UFES e atualmente é pós-graduanda em Educação Especial e Educação Inclusiva. Atua como terapeuta ocupacional na Associação de Pais e Amigos dos Excepcionais - Colatina/ES. Sua área de interesse é saúde mental infantojuvenil.

E-mail: laila_cristinah@hotmail.com

Maria Cristina Cardoso Ribeiro é graduada em Terapia Ocupacional pela UFES e atualmente é pós-graduanda em Educação especial e educação inclusiva. Atua ainda como terapeuta ocupacional na Associação de Pais e Amigos Excepcionais - Viana/ES. Sua área de interesse é saúde mental infantojuvenil.

E-mail: cardoso.cris@live.com

Contato com as autoras:

Rua Moacir Avidos, n. ${ }^{\circ}$ 156/1102

Vitória-ES, Brasil

CEP: 29055-350 